\title{
Study of Optical Properties for (PVA-PEG-ZnO) Nanocomposites
}

\author{
Bahaa H. Rubee ${ }^{1}$, Sara Abd AlHussien ${ }^{2}$ \\ University of Babylon, College of Education for Pure Sciences, Department of Physics, Iraq
}

\begin{abstract}
The aim of this paper, study the effect of zinc oxide on optical properties of (PVA-PEG-ZnO) nanocomposites. The zinc oxide nanoparticle was added to the polymers maxture (polyvinyl alcohol $88 w$ t.\% and Polyethylene glycol 12wt.\%) with different weight percentages are $(0,2,4,6) w t . \%$. The optical properties were measured in the wavelength range (200-800) nm. The results show that the absorbance (A), absorption coefficient $(\alpha)$, extinction coefficient $(k)$, refractive index $(n)$ and real and imaginary dielectric constants $(\varepsilon 1$ and $\varepsilon 2)$ of (PVA-PEG) blend are increasing with the increase of the weight percentages of zinc oxide nanoparticle. The energy gap ( $\left.E_{g}\right)$ of (PVAPEG-ZnO) nanocomposites is decreased with the increase of the zinc oxide nanaparticles concentrations.
\end{abstract}

Keyword: Nanocomposite, Optical Properties, Polyvinyl alcohol, Polyethylene glycol, Zinc Oxide.

\section{Introduction}

Per last year's composite materials attract the rapt attention both in industry applications and in science. In these materials there is the possibility to combine mechanical, electric and optical properties of constituent components in one sample. From optical point of view, several fascinating properties of these composites can be obtained [1]. Generally, the use of most polymers was limited to the manufacture of cheap products which were used for simple purposes. However, the speedy technical development has required the replacement of some materials being used in industry with others having better specifications; consequently, polymers have replaced Aluminum and Iron for some purposes that require stress and high temperature [2] Over the last few years, there are many researches on the natural fibers as loading constituents in composite materials. The biodegradability, low costs, environmental friendliness, low density, non-hazardous, nonabrasive nature and wide variety types of natural fibers are important factors for their acceptance in large volume markets [3] PVA could be considered as a good host material for metal due to its excellent thermostability, chemical resistance, high mechanical strength, water solubility, and moderate and dopant dependent electrical conductivity along with its consideration among the best polymers as host matrix for silver nanoparticles $[4,5]$ (PEG) is known to be highly hydrophilic in its response to water vapour. This makes PEG a favourite material for humidity sensing applications. However, to our knowledge, response mechanism of PEG thin films for a wide range of humidity - say, from 10 to $95 \%$ together with their humidity induced optical and swelling properties have not been investigated in detail [6].

The recent growth in the field of porous and nanometric materials prepared by non-conventional processes has stimulated the search of new applications of $\mathrm{ZnO}$ nanoparticle. Zinc oxide is an interesting semiconductor material due to its application on solar cells, gas sensors, ceramics, catalysts, cosmetics and varistors [7].

\section{Materials and Methods}

The materials which used in this work are polyvinyl alcohol 88 wt. \% and polyethylene glycol 12 wt. \% as a matrix and the zinc oxide nanoparticle as filler. The polymers was dissolved in distill water. The zinc oxide nanoparticle was added to the polymers with concentrations are $(0,2,4,6$ and 8) wt.\%. The casting technique was used to preparation the nanocomposites. The optical properties of (PVA -PEG- $\mathrm{ZnO}$ ) nanocomposites are measured by using UV/1800/ Shimadzu spectrophotometer in range of wavelength (200-800) $\mathrm{nm}$.

\section{Results and Discussion}

Figure 1: shows that the absorbance of composites is increased with the increase of the Zno nanopartical concentration, this behavior attributed to nano particles which absorb the incident light [8]. 


\section{International Journal of Science and Research (IJSR) \\ ISSN (Online): 2319-7064}

Index Copernicus Value (2013): 6.14 | Impact Factor (2015): 6.391

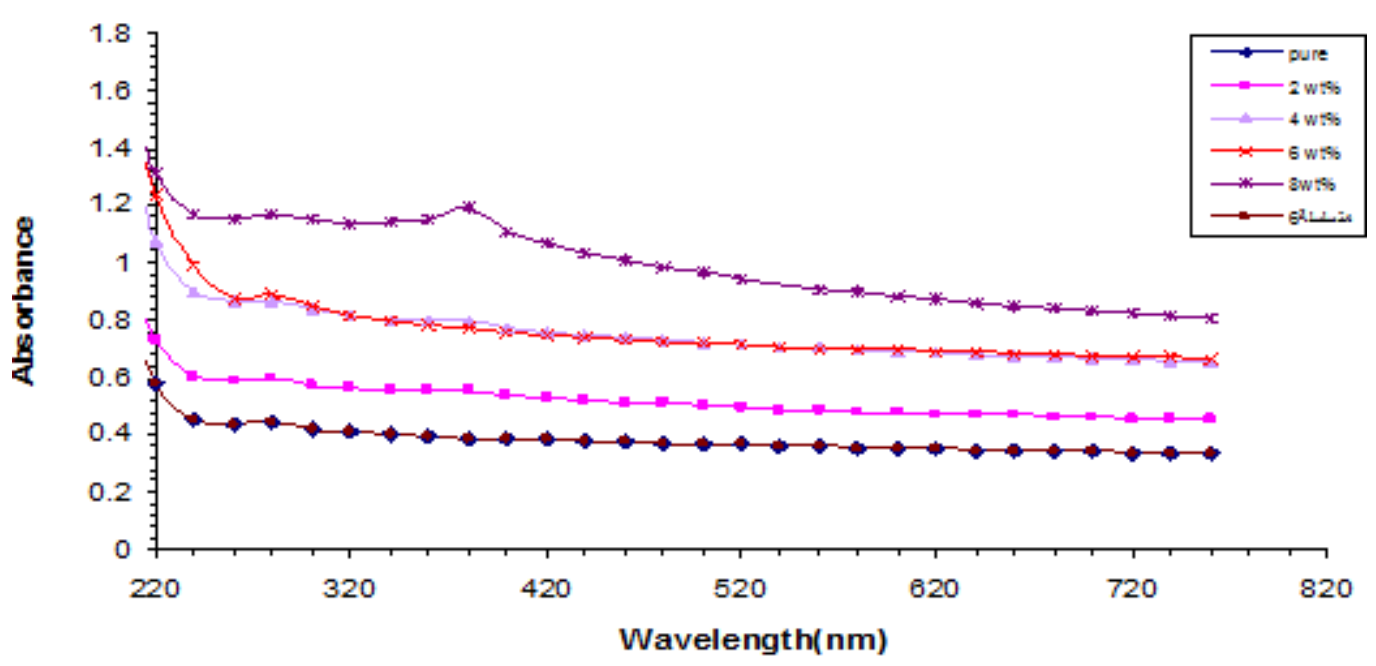

Figure 1: The variation of optical absorbance for (PVA-PEG-ZnO) nano composites with Wavelength

Figure (2) shows an transmittance spectra as a function of incident wavelength for (PVA- PEG- ZnO) nanocomposites.
It can see observe from this figure that the transmittance decreases with increasing of concentration.

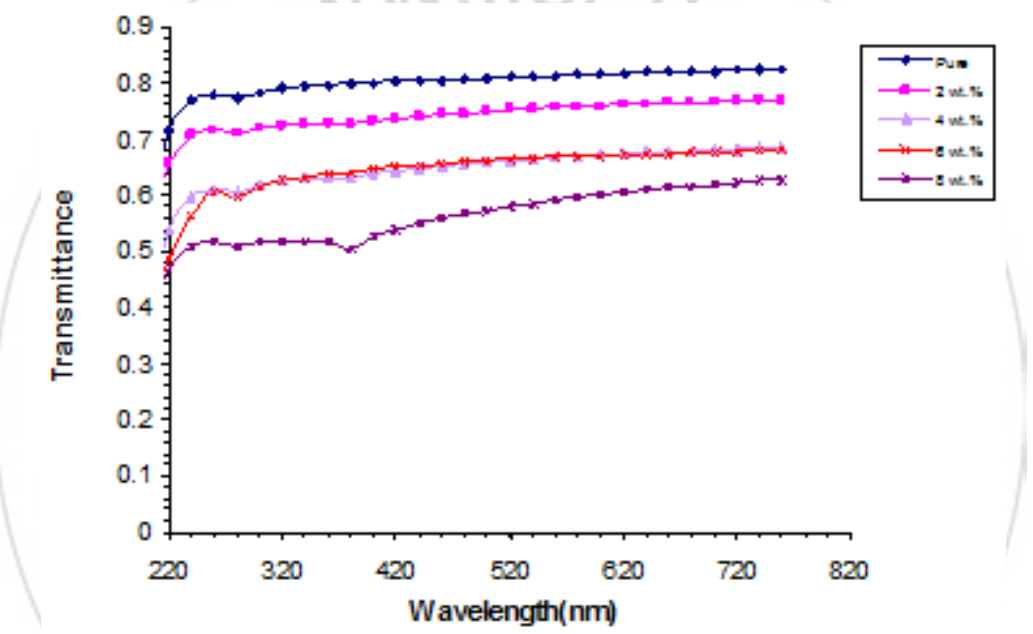

Figure 2: The variation of transmittance for (PVA-PEG-ZnO) nanocomposites with Wavelength.

The absorption coefficient was calculated by follow equation [9]:

$$
\alpha=2.303 \mathrm{~A} / \mathrm{d}
$$

Where: $\mathrm{A}$ is absorbance and $\mathrm{d}$ is the thickness.
The variation of the absorption coefficient $(\alpha)$, as a function photon energy are presented in Figure 2.

(1) The values of the absorption coefficient are less than $10^{4} \mathrm{~cm}^{-1}$ in the investigation spectral range.

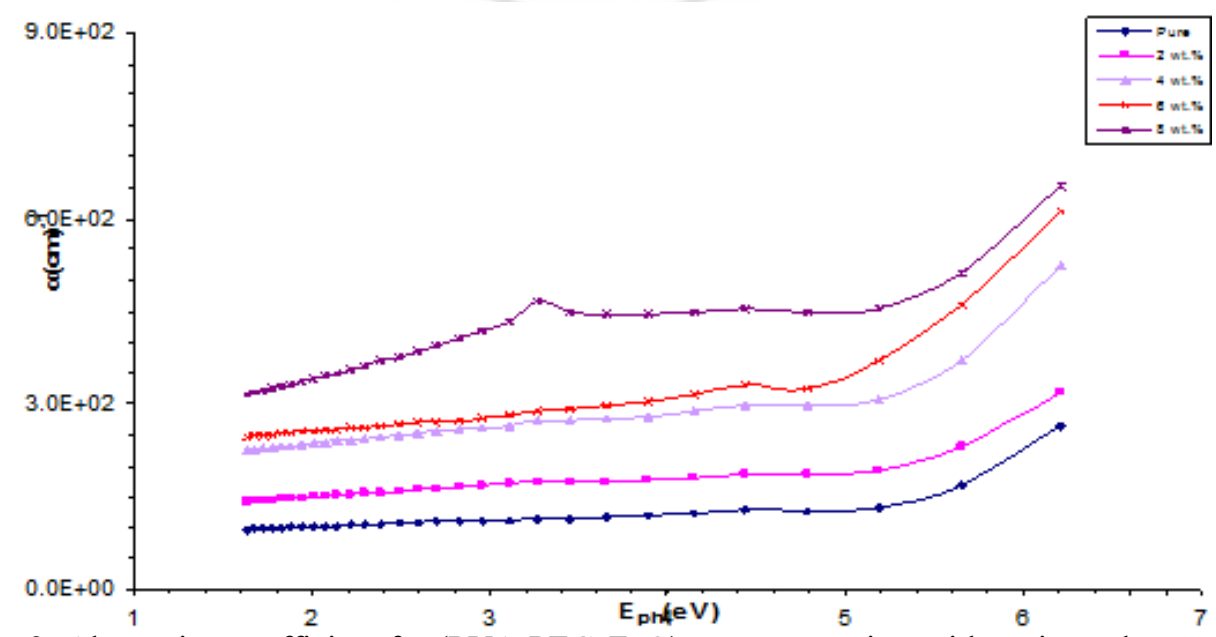

Figure 2: Absorption coefficient for (PVA-PEG-ZnO) nanocomposites with various photon energy 


\section{International Journal of Science and Research (IJSR) \\ ISSN (Online): 2319-7064 \\ Index Copernicus Value (2013): 6.14 | Impact Factor (2015): 6.391}

The fundamental absorption, which corresponds to electron excitation from the valence band to conduction band, can be used to determine the nature and value of the optical band gap $(\mathrm{Eg})$ The relation between the absorption coefficient $(\alpha)$ and the incident photon energy(hv) can be written as [9]. $(\alpha \mathrm{h} v)^{\mathrm{n}}=\mathrm{B}(\mathrm{h} v-\mathrm{Eg})(2)$

Where $B$ is an constant depending on the transition probability and $n$ is an index that characterizes the optical absorption process and is theoretically equal to $1 / 2,2,1 / 3$ or
$2 / 3$ for indirect allowed, direct allowed, indirect forbidden and direct forbidden transition, respectively. The usual method to calculate the band gap energy is to plot a graph between $(\alpha h v)^{n}$ and photon energy (hv) and find the value of the $\mathrm{n}$ which gives the best linear graph. This value of $\mathrm{n}$ decides the nature of the energy gap or transition involved. If an appropriate value of $\mathrm{n}$ is used to obtain linear plot, the value of Eg will be given by intercept on the hv-axis as shown in figure (4 and 5).

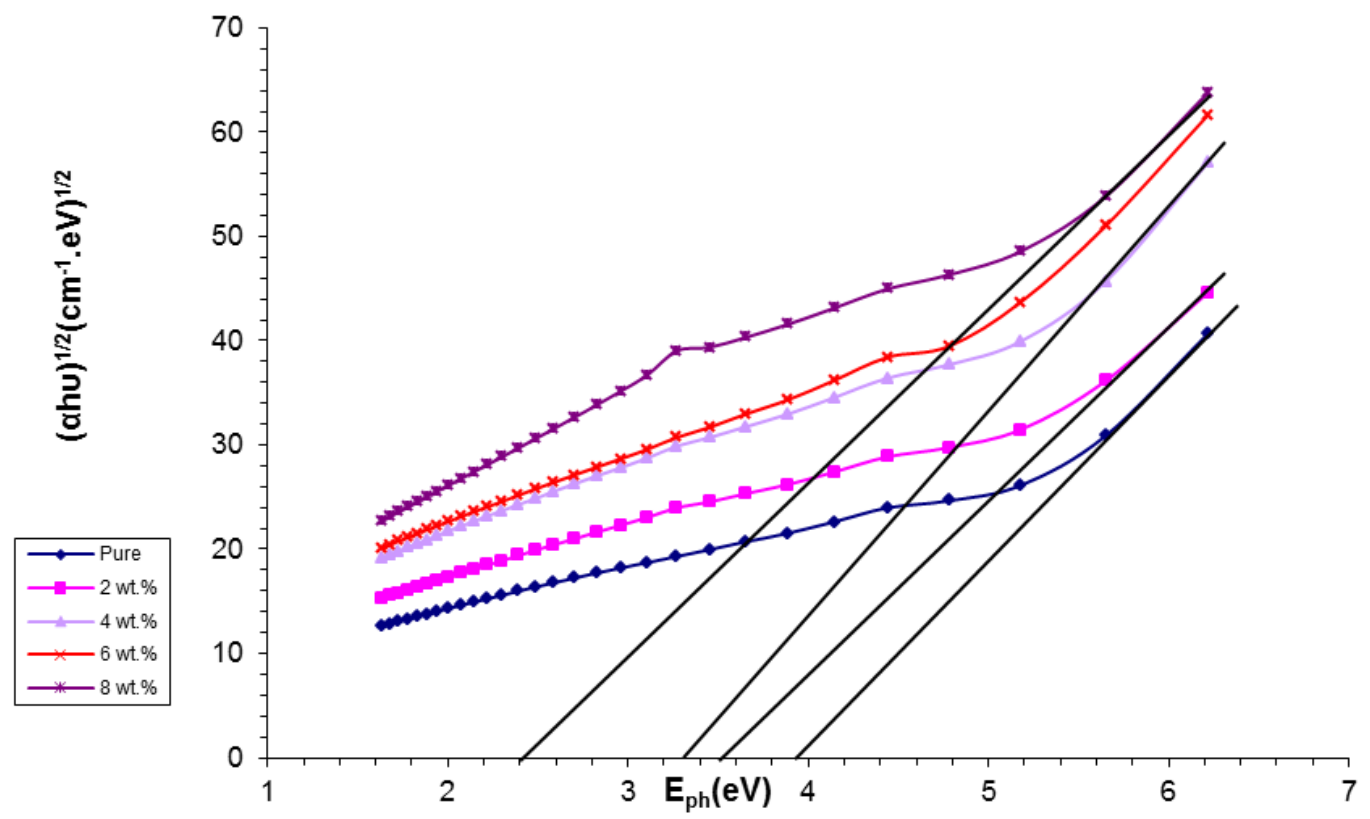

Figure 4: The relationship between $(\alpha \mathrm{hu})^{1 / 2}\left(\mathrm{~cm}^{-1} . \mathrm{eV}\right)^{1 / 2}$ and photon energy of (PVA-PEG-ZnO) nanocomposites.

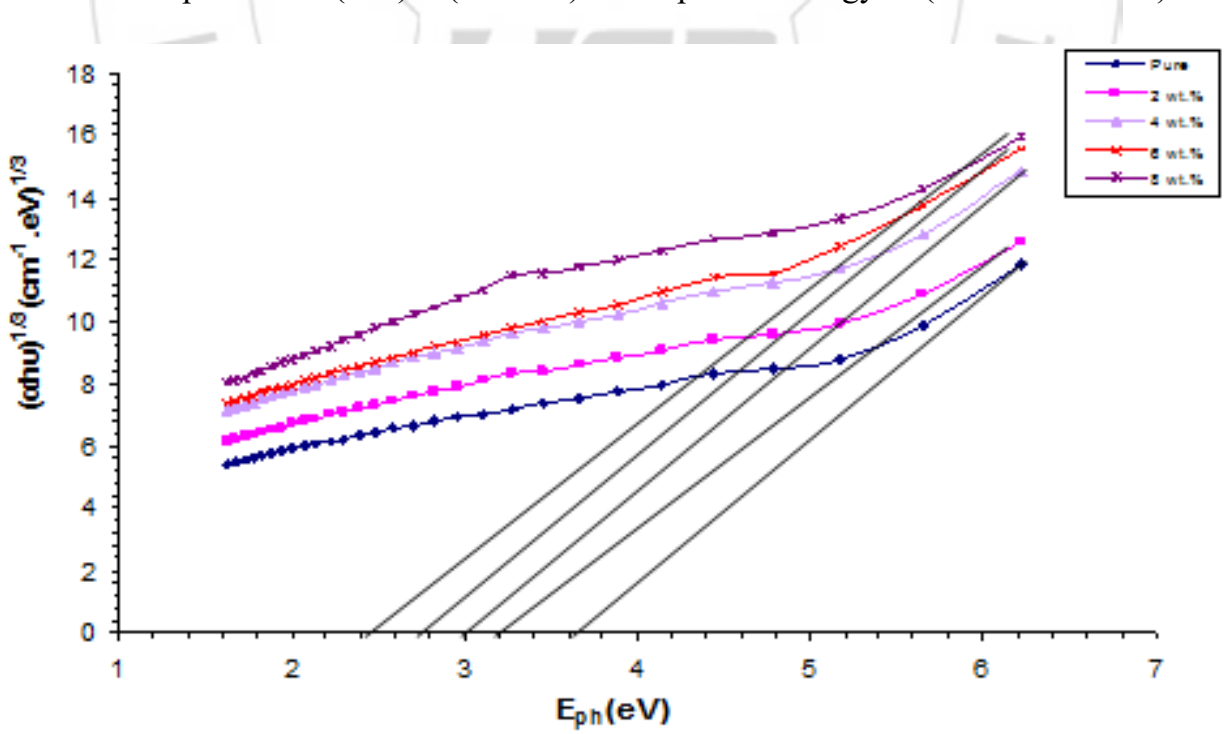

Figure 5: The relationship between $(\alpha h v)^{1 / 3}\left(\mathrm{~cm}^{-1} \cdot \mathrm{eV}\right)^{1 / 3}$ and photon energy of (PVA- PEG-ZnO) nanocomposites

The extinction coefficient is calculated by the relation [10]:

$$
\mathrm{k}=\alpha \lambda / 4 \pi
$$

Where: $\lambda$ is the wavelength, $\alpha$ is the absorption coefficient.
Shows the variation of the extinction coefficient of polymer composites with the photon energy. The extinction coefficient increases with the increase of the Zinkoxide, this attributed to loss of energy because the reaction between the light and the molecules of the medium. 


\section{International Journal of Science and Research (IJSR) \\ ISSN (Online): 2319-7064}

Index Copernicus Value (2013): 6.14 | Impact Factor (2015): 6.391

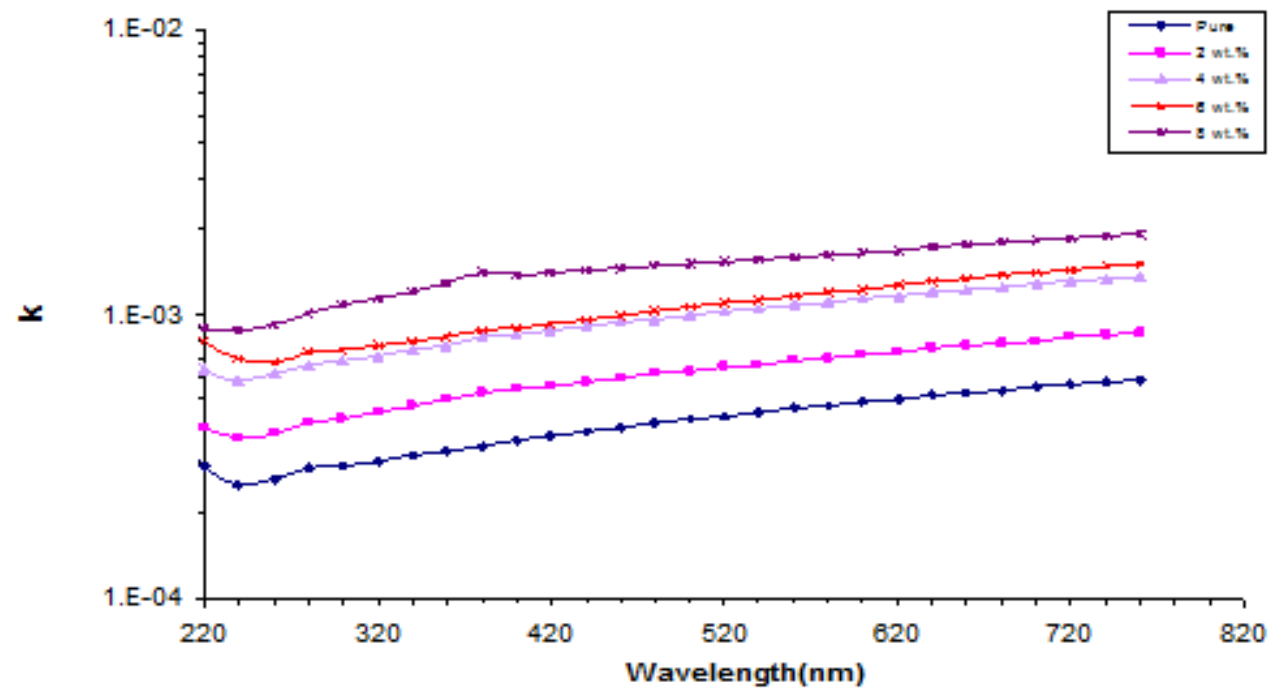

Figure 6: Extinction coefficient for (PVA-PEG-ZnO) nanocomposite with various photon energy

Figure (7) shows the variation of the refractive index $(\mathrm{n}=$ $1+\sqrt{R} / 1-\sqrt{R})$ composites as function of photon energy: where, $\mathrm{R}$ reflectance.

It has been found that the value of refractive index increases with increasing the concentration of nanoparticles of silver

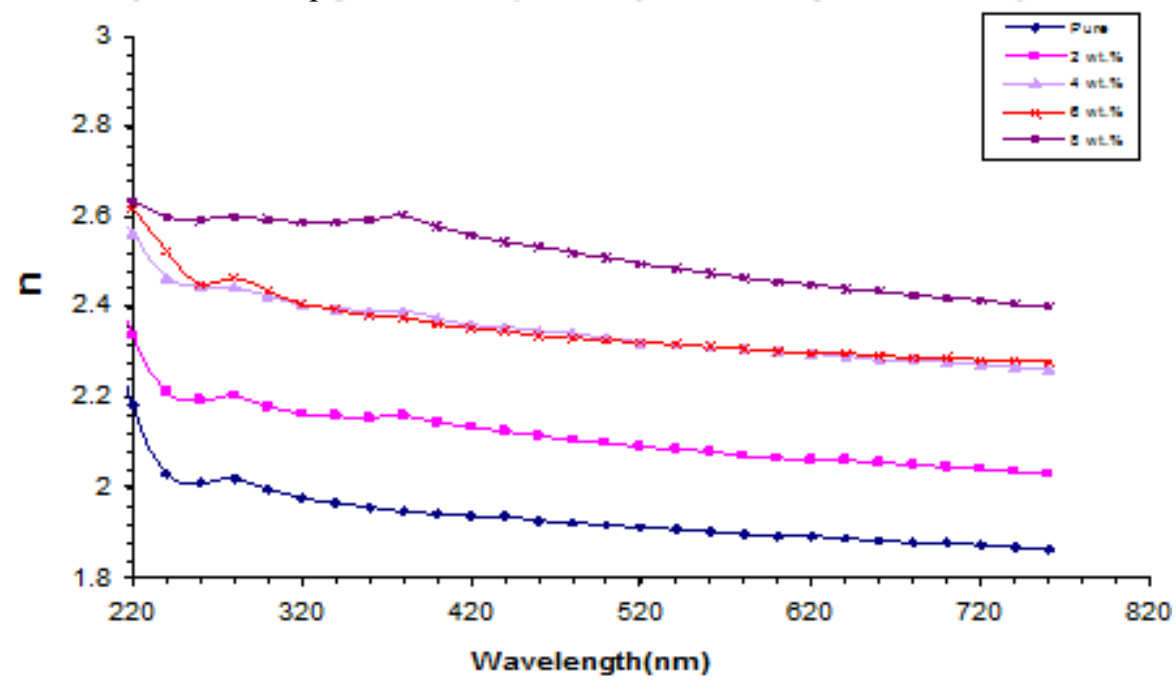

Figure7: The relationship between refractive index (PVA-PEG-ZnO) composite with photon energy

The Figures ( 8 and 9) show the relationship between the real and imaginary parts of dielectric constants nanocomposites with different concentration of filler. From these figures, the real and imaginary parts of dielectric constants are increased with the increase of the concentration of $\mathrm{ZnO}$ nano partical. which is a result of increasing the number atomic refractions due to the increase of the linear polarizability in agreement with Lorentz - Lorentz formula [11].

It is concluded that the variation of $\varepsilon 1$ mainly depends on (n2) because of small values of (k2), while $\varepsilon 2$ mainly depends on the $(\mathrm{k})$ values which are related to the variation of absorption coefficients. The values of the real dielectric constant are high with respect to the imaginary dielectric constant [12]. 


\section{International Journal of Science and Research (IJSR) \\ ISSN (Online): 2319-7064}

Index Copernicus Value (2013): 6.14 | Impact Factor (2015): 6.391

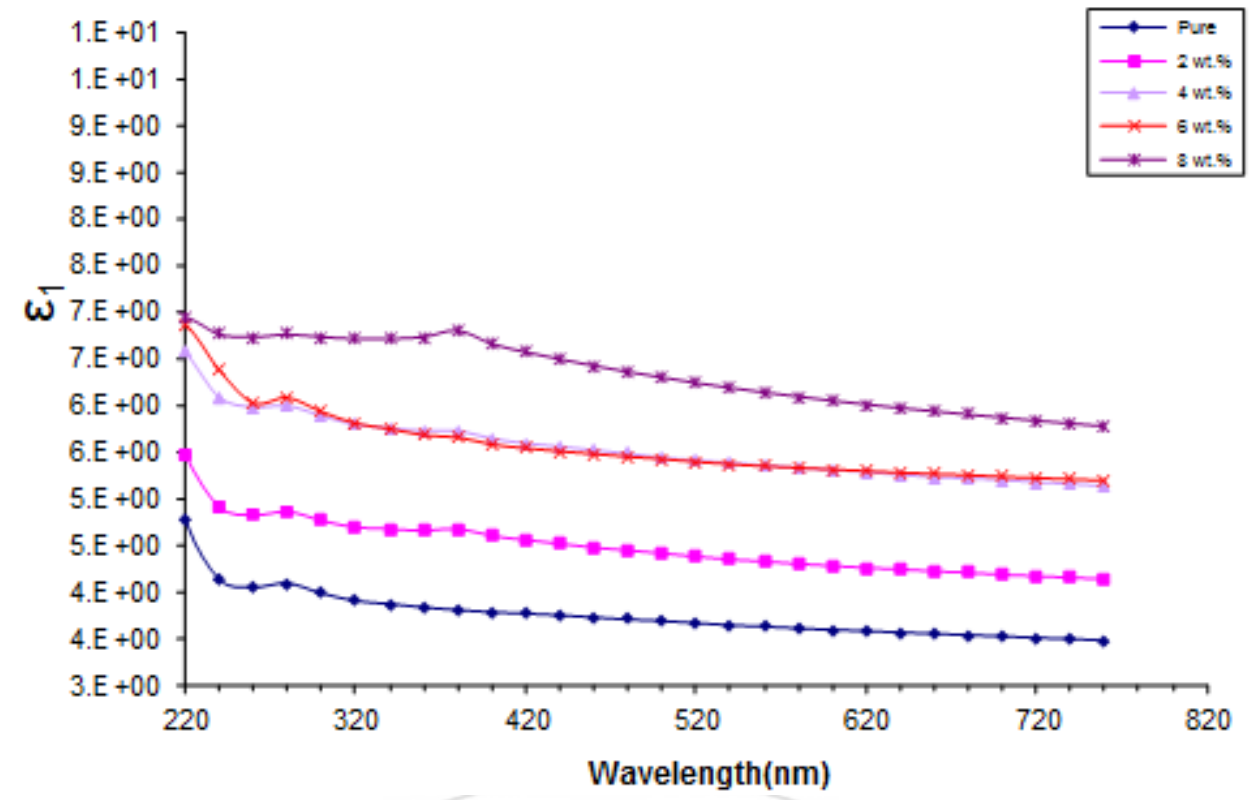

Figure 8: Variation of real part of dielectric constant (PVA- PEG-ZnO) nanocomposite with photon energy.

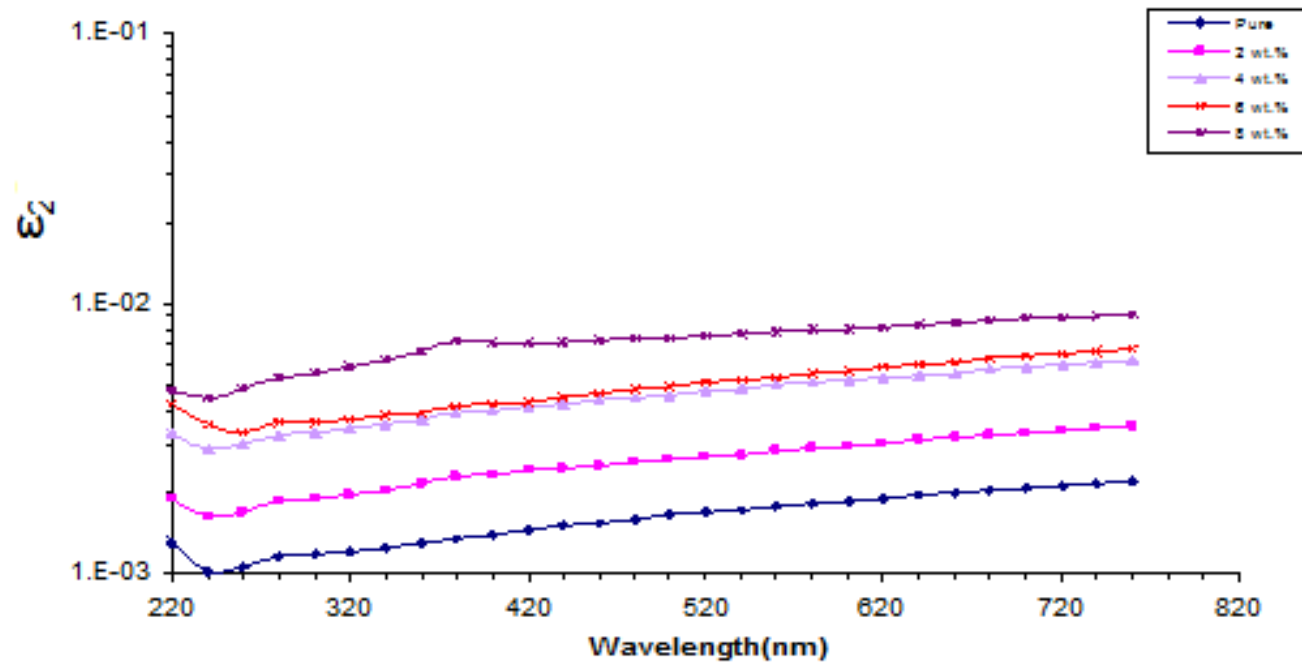

Figure 9: Variation of imaginary part of dielectric constant (PVA-PEG-Zno) composite with photon energy

The optical conductivity oop is obtained by using the relation [13]:

$\sigma_{\text {op }}=\mathrm{nc} \alpha / 4 \pi$

where $\mathrm{c}$ is the velocity of light, $\alpha$ is the absorption coefficient and $\mathrm{n}$ is the refractive index
Figure 10: shows the optical conductivity for (PVA-PEG $\mathrm{ZnO}$ ) nanocomposites films. It is noticed that the optical conductivity increases increases with increasing Zinkoxide nanoparticles [13]. 


\section{International Journal of Science and Research (IJSR) \\ ISSN (Online): 2319-7064}

Index Copernicus Value (2013): 6.14 | Impact Factor (2015): 6.391

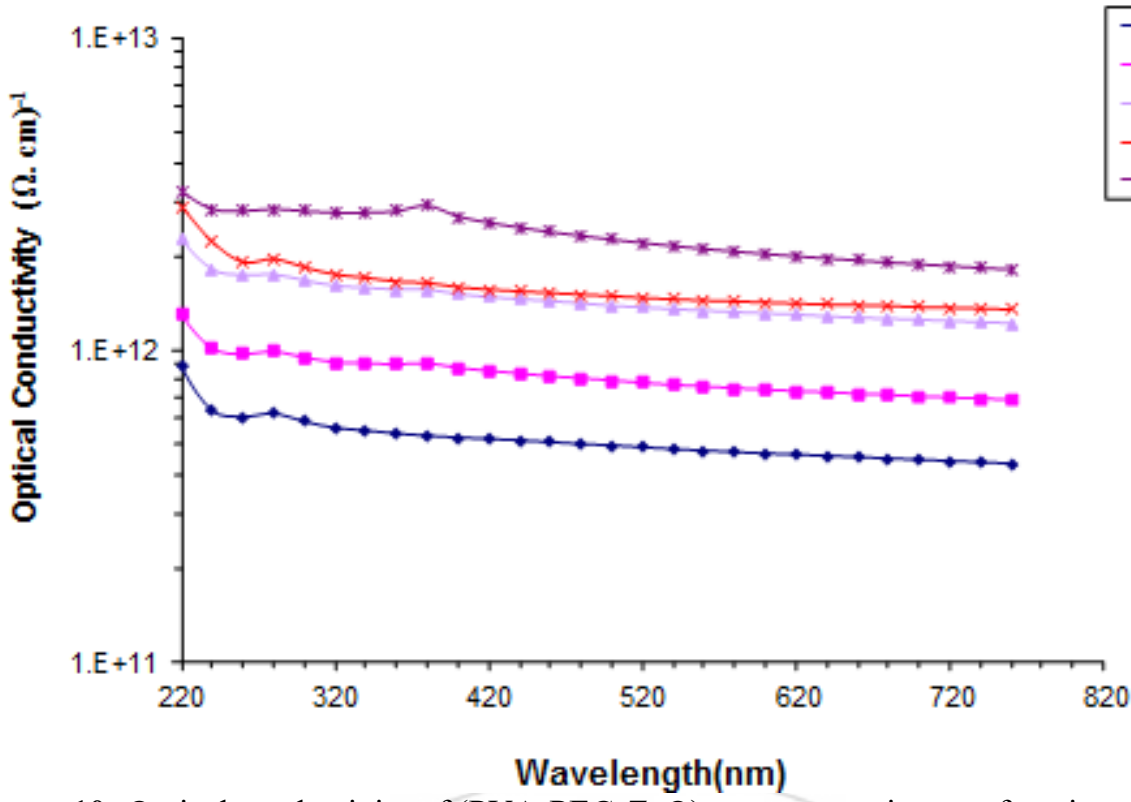

Figure 10: Optical conductivity of (PVA-PEG-ZnO) nanocomposites as afunction of wavelength

\section{Conclusions}

1) The absorbance of (PVA-PEG-ZnO) nanocomposites increases with increase of the concentrations of fillers.

2) The optical constants (absorption coefficient, extinction coefficient, refractive index and real and imaginary dielectric constants) are increasing with increase of the concentrations of zinc oxide nanoparticle.

\section{References}

[1] Kovalchuk, Dolgov, Bugayova, Yaroshchuk, "The Peculiarities of Photo Polymerization in the Composite Pre-Polymer- $\mathrm{TiO}_{2}$ Nanoparticles", J. of Mol. Cryst. Liq. Cryst., Vol. 427, P. 191-200, (2005)..

[2] G. A. Kontos, A. L. Soulintzis and P. K. Karahaliou, J. "Electrical Relaxation Dynamics in $\mathrm{TiO}_{2}$-Polymer Matrix Composites". Express polymer Letters, Vol. 1, No. 12, P. 781-789, (2007).

[3] A. N Ananth and S. Umapathy, "On the Optical and Thermal Properties of in Situ/ex Situ Reduced Ag NP's/PVA Composites and its Role as a Simple SPRBased Protein Sensor, " Applied Nanoscience, Vol. 1, No. 2, P. 87-96, (2011).

[4] G. Fussell, J. Thomas, J. Scanlon, A. Lowman, and M. Marcolongo, "The Effect of Protein-Free Versus Protein-Containing Medium on the Mechanical Properties and Uptake of Ions of PVA/PVP Hydrogels, " Journal of Biomaterials Science, Vol. 16, No. 4, P. 489-503, (2005).

[5] A. Ashori, "Wood-Plastic Composites as Promising Green Composites for Automotive Industries, " Bioresource Technology, Vol. 99, No. 11, P. 46614667, 2008).

[6] S. Acikgoz, B. Bilen, M. M.Demir, Y.Ziya Menceloglu, Y. Skarlatos, G. AKTAS, and M.Naci Inci "Use of Polyethylene Glycol Coatings for Optical Fibre Humidity Sensing" Optical Review Vol. 15, No. 2, P. 84-90, (2008).

[7] H. Meruvu, M.Vangalapati, S. C. Chippada and S.R. Bammidi "Synthesis and Characterization of Zink
Oxide nanoparticles and Its Antntimicrobial Activity Against Bacillus Subtitillis and Escherichia Coli" Vol.4, No.1, P. 217-222, (2011).

[8] Z.Ramdhan, M.Ali, A. Khalaf, A. Hashim, H. Hakim," Optical Properties of (PVA-PEG-PF, PP) Composites ", International Journal of Science and Research (IJSR), Vol. 3, Issue 10, (2014).

[9] A. Hashim, M.Ali, Bahaa. H. Rabee, " Optical Properties of (PVA-CaO) Composites ", American Journal of Scientific Research, Vol. 2012, Issue 69, P. 5-9, (2005).

[10] G. Attia and M.F.H. Abd El-kader, Structural, " Optical and Thermal Characterization of PVA/2HEC Polyblend Films", Int. J. Electrochem. Sci., Vol. 8, P. 5672 - 5687, (2013).

[11]B. H. Rabee, T. N. Khudair " Study of Optical Properties for $\left(\mathrm{PS}-\mathrm{Y}_{2} \mathrm{O}_{3}\right)$ Nanocomposites", International Journal of Science and Research (IJSR), Vol.4, Issue 6, (2015).

[12] V. S. Sangawar and M.C. Golchha, "Evolution of the Optical Propertiesof Polystyrene Thin Films Filled with Zinc Oxide Nanoparticles", International Journal of Scientific \& Engineering Research, Vol 4, Issue 6, (2013).

[13] R. Tintu' K. Saurav, K. Sulakshn a, V P N Nampoori, P Radhakrishnan, Sheenu Thomas' " $\mathrm{Ge}_{28} \mathrm{Se}_{60} \mathrm{Sb}_{12}$ /PVA Composite Films for Photonic Applications " Vol. 2, No 4, P. 167- 174 (2010). 